\title{
Antibacterial effect of mouthwash containing CPC against dental caries caused bacteria
}

\author{
Won-Ho Cho ${ }^{1}$, Ja-Won Cho ${ }^{1}$, Hyun-Jun Yoo ${ }^{1}$, Kyong-Hoon Shin ${ }^{2}, \mathrm{Gi}-\mathrm{Hae} \mathrm{Shin}^{2}$, Yeol-Mae Jeon ${ }^{1}$, \\ Jong-Cheon Lee ${ }^{1}$ \\ ${ }^{1}$ Department of Preventive Dentistry, College of Dentistry, Dankook University, Cheonan, \\ ${ }^{2}$ Aekyung Industrial Co., Ltd. R\&D Division Dental Care Team, Daejeon, Republic of Korea
}

Objectives: The purpose of this study was to evaluate and report the antibacterial efficacy in relation to oral disease-causing bacteria using a mouthwash containing $0.05 \% \mathrm{CPC}$ in an in vitro test.

Methods: The sterilization test and susceptibility assay of mouthwash containing $0.05 \%$ CPC were investigated against Streptococcus mutans, Streptococcus sobrinus, and Lactobacillus acidophilus; Streptococcus sanguinis as oral bacteria related to dental caries; Enterococcus faecalis as apical periodontitis-related bacteria; and Actinomyces israelii, Aggregatibacter actinomycetemcomitans, Fusobacterium nucleatum, Prevotella intermedia, Prevotella nigrescence, Porphyromonas gingivalis, Tannerella forsythia, Treponema denticola, and Filifactor alocis as periodontal disease-related bacl-teria.

Results: In the sterilization test, most of the bacteria had more than $99.99 \%$ sterilizing power for all samples but compared to other bacteria, the sterilizing power of these samples was not successful for L. acidophilus and E. faecalis bacteria. When comparing the sterilization power between the samples, sample $3(0.05 \% \mathrm{CPC}+20 \%$ ethanol) was the strongest.

Conclusions: In the antimicrobial activity test, sample 3 inhibited growth at the lowest concentration overall.

Key Words: Cetylpyridinium chloride, Mouthwashes, Streptococcus mutans

Copyright (C) 2021. Korean Academy of Preventive Dentistry. All rights reserved.

This is an Open Access article distributed under the terms of the Creative Commons Attribution Non-Commercial License (http://creativecommons.org/licenses/ by-nc/4.0) which permits unrestricted non-commercial use, distribution, and reproduction in any medium, provided the original work is properly cited. 